\title{
ICAPA-HD: Hazard Detection Methods for Improving Overdose Prevention
}

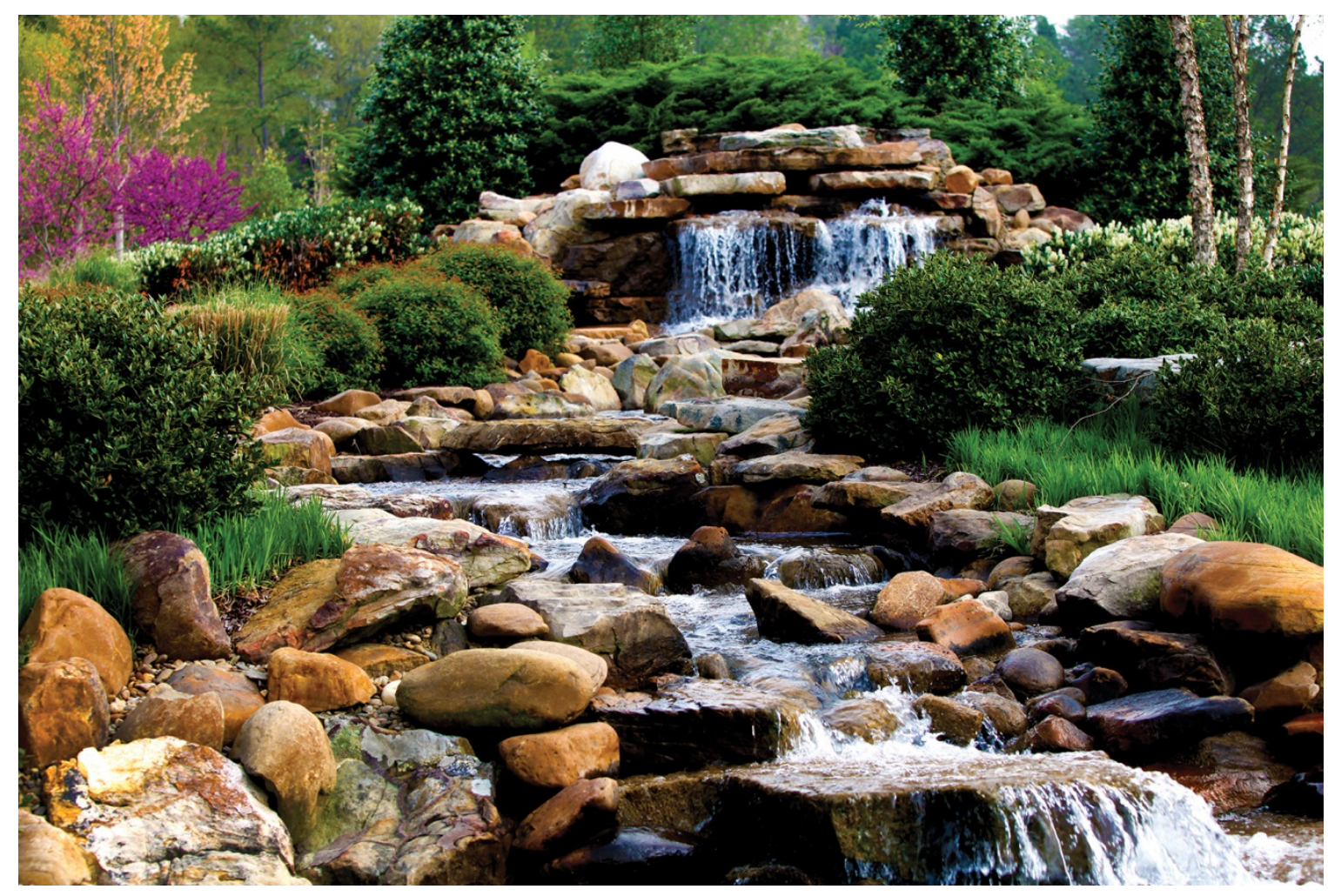

Olufemi Omitaomu

Ozgur Ozmen

Haoran Niu

Hilda Klasky

Mohammed Olama

September 2021

\section{OAK RIDGE




\title{
DOCUMENT AVAILABILITY
}

Reports produced after January 1, 1996, are generally available free via US Department of Energy (DOE) SciTech Connect.

Website www.osti.gov

Reports produced before January 1, 1996, may be purchased by members of the public from the following source:

\author{
National Technical Information Service \\ 5285 Port Royal Road \\ Springfield, VA 22161 \\ Telephone 703-605-6000 (1-800-553-6847) \\ TDD 703-487-4639 \\ Fax 703-605-6900 \\ E-mail info@ntis.gov \\ Website http://classic.ntis.gov/
}

Reports are available to DOE employees, DOE contractors, Energy Technology Data Exchange representatives, and International Nuclear Information System representatives from the following source:

Office of Scientific and Technical Information

PO Box 62

Oak Ridge, TN 37831

Telephone 865-576-8401

Fax 865-576-5728

E-mail reports@osti.gov

Website https://www.osti.gov/

This report was prepared as an account of work sponsored by an agency of the United States Government. Neither the United States Government nor any agency thereof, nor any of their employees, makes any warranty, express or implied, or assumes any legal liability or responsibility for the accuracy, completeness, or usefulness of any information, apparatus, product, or process disclosed, or represents that its use would not infringe privately owned rights. Reference herein to any specific commercial product, process, or service by trade name, trademark, manufacturer, or otherwise, does not necessarily constitute or imply its endorsement, recommendation, or favoring by the United States Government or any agency thereof. The views and opinions of authors expressed herein do not necessarily state or reflect those of the United States Government or any agency thereof. 
Computational Sciences and Engineering Division

\title{
ICAPA-HD: HAZARD DETECTION METHODS FOR IMPROVING OVERDOSE
} PREVENTION

\author{
Olufemi Omitaomu \\ Ozgur Ozmen \\ Haoran Niu \\ Hilda Klasky \\ Mohammed Olama
}

September 2021

Prepared by

OAK RIDGE NATIONAL LABORATORY

Oak Ridge, TN 37831-6283

managed by

UT-BATTELLE LLC

for the

US DEPARTMENT OF ENERGY

under contract DE-AC05-00OR22725 



\section{CONTENT}

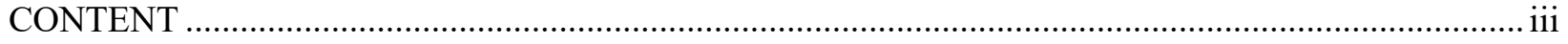

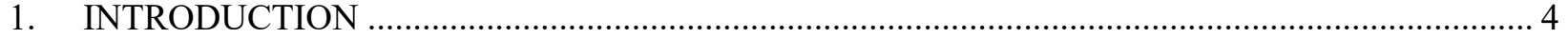

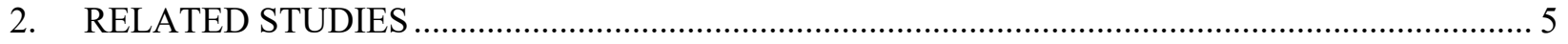

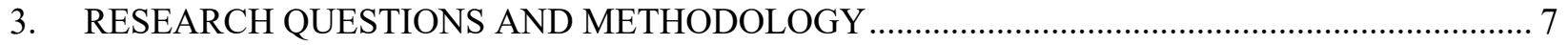

3.1 DATA FOR INITIAL OVERDOSE EVENT SELECTION …....................................... 7

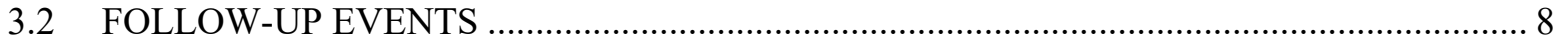

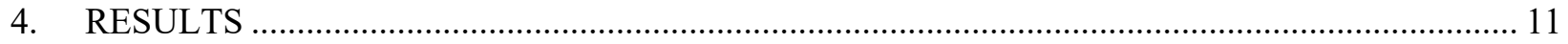

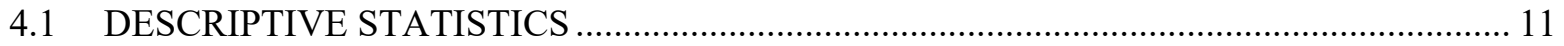

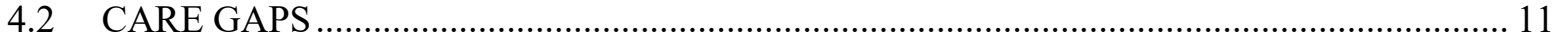

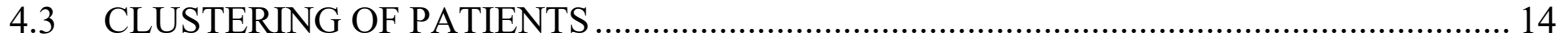

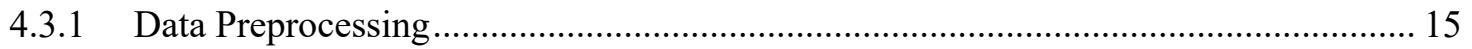

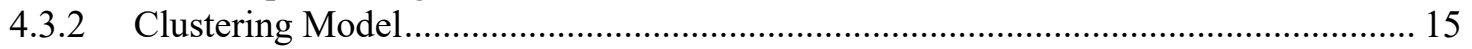

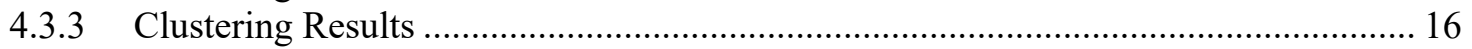

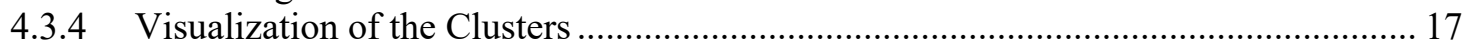

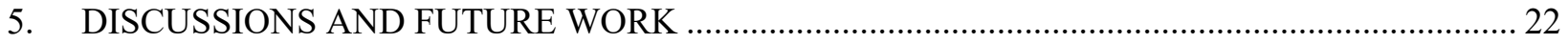

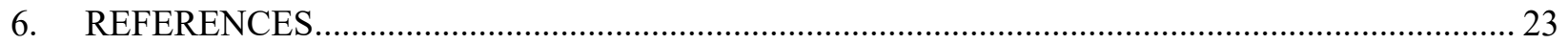




\section{INTRODUCTION}

In the United States (US), deaths due to suicide and unintentional overdose is a major, and growing, public health concern. Emerging data [1] suggest that the increases in overdose and suicide deaths are interconnected; however, there is evidence [2] that strategies that address the intersections between opioid use, overdose, and suicide have been largely unexamined. Shared and synergistic risk factors for suicide and overdose include mental health disorders, substance use disorder, non-fatal overdose, suicidal ideation or attempts, intimate partner problems, poor social support, childhood trauma, and some chronic conditions [1], [3]. According to [2], the opioid epidemic can be better tackled by "concurrently promoting comprehensive suicide overdose prevention to address the intersecting needs of people at risk."

From a public health perspective, the time after a nonfatal event provides a critical engagement opportunity to reduce subsequent overdoes or suicide risk and link individuals to treatments. Specifically, the time after a nonfatal overdose provides an opportunity to identify high-risk individuals and engage them in treatment and harm reduction strategies to reduce their future overdose risk. There is a standard care process after an opioid overdose. However, there is a significant variation in what normally happens; hence, missed opportunities for adequate care. Some post-event interventions usually fall short through breakdown in the consultation processes after an appearance at the Emergency Department (ED). Improving post overdoses or suicide attempts care could reduce patients' risk factor to overdoes or suicide. The Veterans Health Administration (VHA) seeks to develop new methods for tackling breakdown in interventions for veterans after nonfatal events with special focus on the consultation processes after treatments in the ED.

The Oak Ridge National Laboratory (ORNL) research team in this project has focused on developing methods for improving overdose prevention by addressing three unresolved issues, divided into two groups, that could impact interventions:

\section{Understanding Events with Bad Outcomes:}

- Identifying the level of opioid misuse that could improve risk detection and/or provide an indicator for clinical intervention.

$\Rightarrow$ Sample research question: Could patterns of (relevant) drugs prescribed to opioid use disorders (OUD) (and/or substance use disorders (SUD)) patients increase their risk for overdose and OUD/SUD development?

- Detecting "rapid" opioid tapering activities that can result in patient transition to alternative drugs or may result in uncontrolled pain, which can in turn increase suicidality.

$\Rightarrow$ Sample research questions: Is there evidence from (labeled) pharmacy notes that could provide some insights about "rapid" opioid tapering activities? Could similar approaches be used for rapid tapering in other medications? 


\section{Understanding Events with Better Outcomes:}

- Identifying the prevention strategies with higher payoff using the available data.

$\Rightarrow$ Sample research questions: What does a well-defined evidence-based pharmacotherapy mean for prescription patterns? How about specialty care?

\section{RELATED STUDIES}

VHA has supported research programs that seek to confront the opioid use disorder observed within a subset of the US veterans' population. A brief outline of previous work performed by those VHA programs is presented in this section to provide context for the ORNL research team on opioid use disorder currently underway for the VHA.

Oliva et al. [4] provided a review of VHA's national program for opioid Overdose Education and Naloxone Distribution (OEND), focused on patients with opioid use disorders as well as patients prescribed opioid analgesics. Key innovations from that nation-wide program included the following:

- developing steps to implement OEND,

- pharmacy developing standard naloxone rescue kits,

- adding those kits to the VHA National Formulary,

- centralizing kit distribution,

- developing clinical guidance for issuing naloxone kits,

- supporting OEND as a focal campaign of academic detailing,

- developing patient and provider education resources (e.g., brochures, videos, accredited training), and

- implementing and evaluating resources (e.g., technical assistance, clinical decision support tools, etc.).

In a related article, Oliva et al. [3] described the VHA launch of an Opioid Safety Initiative in the form of the Stratification Tool for Opioid Risk Mitigation (STORM), a tool developed for the VHA that reflects a holistic approach dealing with both risk factors (e.g., dose, substance use disorders) and risk mitigation interventions (e.g., urine drug screening, psychosocial treatment). Specifically, STORM facilitates both patient identification and monitoring.

As in 2013, the VHA began implementing the opioid program OEND to combat opioid overdose mortality among veterans in 2016. Oliva et al. [5] presented a study that examined the patient perspective about OEND training and the naloxone kits. The authors reported that the training was generally well-received among study participants. Veterans thought OEND training was interesting, novel, and empowering, and that naloxone kits would save lives. Some veterans expressed concern about using syringes in the kits. A few patients who never used opioids were not interested in receiving kits. Veterans offered different opinions about legal and liability issues, whether naloxone kits might contribute to relapse, and whether and how to involve the family in training. Some veterans expressed uncertainty about the effects of naloxone. Suggested 
improvements included active learning approaches, enhanced training materials, and increased advertisement.

The VHA-sponsored programs have produced additional insights concerning the opioid overdose issue, several examples of which are given below:

- Lin et al. [6], observed varying tendencies in opioid overdose deaths in the population of US veterans. Unfortunately, overdose rates among veterans increased in 2016 because of the increases in heroin and synthetic opioid overdose rates. However, the authors noted a decline in methadone overdose and no significant change in natural/semisynthetic opioid overdose.

- Mudumbai et al. [7] presented a study on overdose risk associated with opioid use following hospital discharge of VHA surgical patients. They concluded that surgical patients should be treated with the lowest effective intensity of opioids and be monitored to prevent opioidrelated adverse events.

- Oliva et al. [8] presented a study of associations among opioid-related factors, including the stopping prescriptions for opioids, the length of opioid treatment, and overdose or suicide deaths in US veterans. They noted that discontinuing treatment was linked with an augmented risk of death from overdose or suicide, regardless of the span of the health care treatment, with the risk increasing the longer patients were treated.

Other studies that focus on how to improve VHA patient engagement during follow-up care include the following examples:

- Koh et al. [9] proposed a health literature care model to improve patient engagement in care. This model is based on the Care Model [10] but includes an activity to provide knowledge to the patients so they can engage in their own health care process. The model assumes all patients are at risk of not understanding their health conditions or how to deal with them, and then, afterward verifying and ensuring patients' understanding by asking appropriate questions.

- Langebeer II et al. [11] observed an overall increase in patient engagement in telehealth during COVID-19 for overdose user disorder patients. Thus, telehealth is an approach that is gaining popularity and success.

- As of 2020, apparently, little is known about follow-up care after resuscitation of patients who experience overdose during an outbreak, Massey et al. [12] found that none of the opioid overdose patients who met case criteria received a referral for substance use disorder treatment or harm in his investigation of a nonfatal opioid overdose outbreak that occurred in Huntington, West Virginia, on August 15, 2016. Consequently, the authors suggested the development of public health and public safety partnerships for substance identification, and of strategies to link overdose patients to recovery support services at the point of resuscitation. The latter may reduce missed opportunities to engage patients after an overdose.

- Tsal et al. [13] developed a typology of the stigma related to opioid use, showing how multiple dimensions of stigma continue to fundamentally hinder the response to the crisis at all levels and for all parties involved. The authors also pointed out the need for more 
research in this regard to understand and address the stigma in opioid overdose and to foster the implementation of interventions.

- Carroll et al. [14] presented a set of successful case series in prehospital emergency care of buprenorphine field initiation of ReScue Treatment to illustrate a new treatment paradigm. They suggested using larger doses of the medication for patients exhibiting signs and symptoms of withdrawal.

- Langebeer et al. [15] presented an approach for emergency medical services outreach for overdose survivors. This framework is based on rapid response to post-overdose survivors by a team, comprised of a peer recovery coach and a paramedic, to the home location of that recent overdose survivor.

The foregoing discussion has presented an array of VHA - supported research programs addressing a multiplicity of strategies that focus on the common goal of confronting the opioid use disorder observed among US veterans, as well as a selection of work performed outside the VHA in this matter. In the following sections, ORNL research is described that seeks to build on the above VHA record by looking into follow-up care records from the VHA Corporate data warehouse (CDW) after an initial event that is considered to trigger a series of follow-up actions. In this work, the ORNL team focuses on a subset of overdose events as initial events, presents the data as a time sorted event sequence for patients, and answers a couple of simple but effective research questions to better understand the prevalence of the follow-up care and what are the potential points that the care might be broken.

\section{RESEARCH QUESTIONS AND METHODOLOGY}

This effort is a short-term project that is designed to understand the data around initial overdose events and provide some insights. There are three individual tasks/questions we aim to address:

1. Providing descriptive statistics for the patients who had certain follow-up events and how those numbers evolve when the care is broken into time buckets (the proportion of patients who had mental health visits in 7 days, 14 days, etc.).

2. Studying care gaps. What are the distributions of time between encounters for the patients who had another ED visit with overdose or Suicide Behavior and Overdose Events (SBOR) suicide event in the next 30 days, 60 days, 90 days, and 6 months, etc.? In this case, encounters will be any day patients showed up in the system - such as filling naloxone, or inpatient or outpatient visits.

3. Find clusters of patients who follow the most common paths/patterns (patients who do not have any follow-up visits, patients who had follow-up visits but had no Comprehensive Suicide Risk Evaluation (CSRE) or SBOR record, etc.) and compare their proportions in the overall group. This is an exploratory task that will use process maps to develop an understanding of the follow-up event data.

\subsection{DATA FOR INITIAL OVERDOSE EVENT SELECTION}

The main data source of this project is the VHA CDW. Members of the VHA shared multiple queries with ORNL to extract different data elements from CDW that are relevant to overdose events. These data elements are: (i) SBOR reports that are self-reported and can be extracted 
from Health Factors tables, (ii) ED visits (Stop codes 130 and 131) with overdose diagnosis ${ }^{1}$, (iii) Inpatient visits that are mental health related or residential ${ }^{2}$.

The SBOR events are self-reported, and they can be a distant past event relative to the report date. So, we only considered overdose SBOR events that happened less than 90 days before the report date. We found the SBOR events based on the event type (for Accidental overdose or Overdose event) and the method of suicide (as overdose for Suicide events and Possible Suicide events). Regarding the ED visits, we basically extracted the visits that have a primary or secondary diagnosis as one of the overdose codes (ICD10). Inpatient visits are the visits that ended up at mental health or residential bed sections (treating specialties). All these events are collected starting from the $1^{\text {st }}$ of February 2019 since SBOR reports started to be widely used after that date.

To find the first overdose event at which VHA became familiar with the overdose, we mixed these three types of events in the same bucket and selected the first one that occurred. The assumption is: VHA would initiate follow-up care for these patients when they get aware of the overdose, and we can distinguish these follow-up events by following these patients in the succeeding months. Figure 1 explains the selection of the initial event.

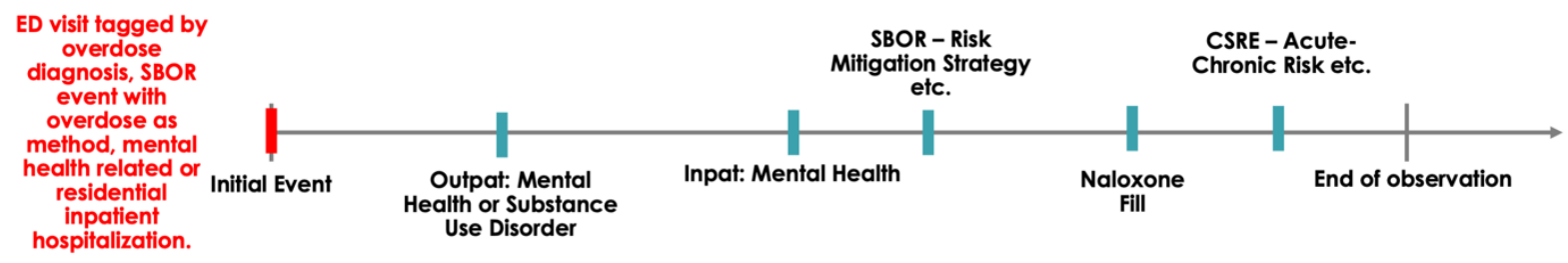

Figure 1 Selection of an initial event and the follow-up events that are observed.

We found that between February $1^{\text {st }}$ of 2019 and June $1^{\text {st }}$ of 2021 , there were 31,757 patients who had one of the initial events. We collected follow-up events for these patients. The next section explains the specific follow-up events that were collected.

\subsection{FOLLOW-UP EVENTS}

Follow-up events consist of events that are from SBOR reports, CSRE reports, Outpatient visits, Inpatient visits, Naloxone prescriptions, and Death ${ }^{3}$ information from the Master Veteran Index (MVI). SBOR events are basically new suicide events, Risk mitigation Strategies, Risk Factors, Protective Factors, and Warning Signs recorded. CSRE events include Acute-Chronic risk of suicide, Risk Factors, Protective Factors, and Warning Signs. Only mental health-related and residential inpatient hospitalizations are included. Regarding Outpatient visits, we only included mental health and SUD related visits. Naloxone refills are limited to the rescue kits that are ordered as prevention, and they are extracted from the RxOut tables based on a query shared by

\footnotetext{
${ }^{1}$ These codes are part of the Drug Overdose Surveillance and Epidemiology (DOSE) System and shared by Elizabeth Oliva.

2 The bed sections are shared with ORNL by the Patient and Family Education Center (PERC).

${ }^{3}$ Naloxone medications code investigates the rescue kits, and the code is shared with ORNL by Elizabeth Oliva from VHA.
} 
VHA. Consequently, we established a data model which includes these events sorted per patient, starting from the initial event (see Figure 2).

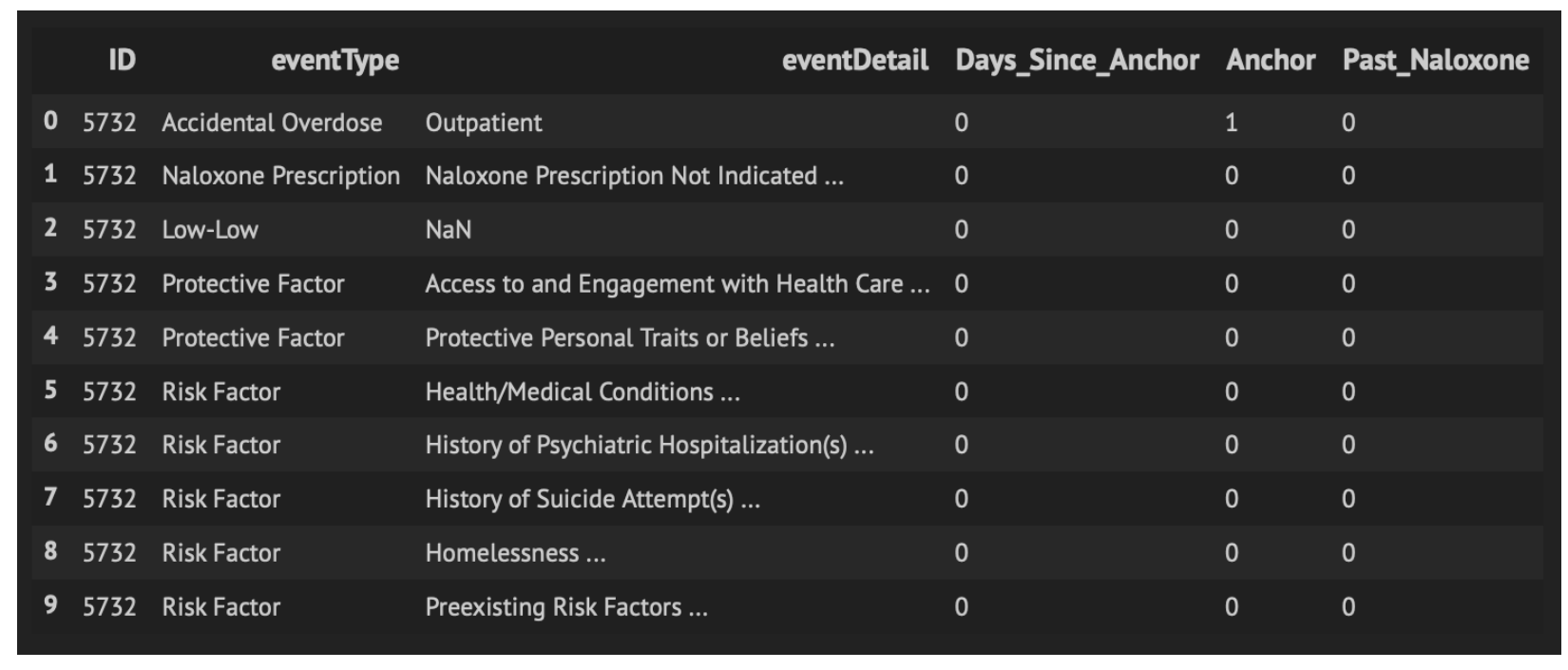

Figure 2 Data model structure that has events per patient as a list sorted by time.

Time is represented as a relative metric that is the number of days passed since the initial event (Days_Since_Anchor column). The anchor column represents whether the event is the initial event. Past_Naloxone represents the past Naloxone fill flag for the patient that was before the initial event. EventType is the main event type and eventDetail includes a variety of details about the event (i.e., what option was selected from the SBOR and CSRE template, was the event inpatient or outpatient, was it intentional or unintentional). ID is the patient identifier that had been de-identified before the data was egressed from the CDW.

Figure 3 presents a process model map (a graph) that depicts the flow of the events in our data. The process maps that incorporate all the patients are very cluttered and difficult to read, Thus, for clarity, this figure depicts the process map showing the frequency of events for a couple of cases. We can observe that a patient that has an accidental overdose, has a Naloxone prescription, then protective and risk factors are evaluated, then risk mitigation strategies are implemented, then warning signs may be stored in the system, which is followed by MANY Outpatient $\mathrm{MH}$ visits. After this, one patient case was given Naloxone again, and finally, there were Outpat SUD appointments. Note that the numbers near the arrow represent frequencies. And that SUD visit numbers are smaller than the Outpatient $\mathrm{MH}$ visits numbers.

All software programs developed in this study are stored at a Git ${ }^{4}$ repository in the Knowledge Discovery Infrastructure (KDI) environment ${ }^{5}$.

\footnotetext{
${ }^{4}$ Git is a software configuration management system that helps to track changes to software programs and files.

5 The repository is named sbor_csre in https://code-va.kdi.local/ inside the enclave (no access from outside).
} 


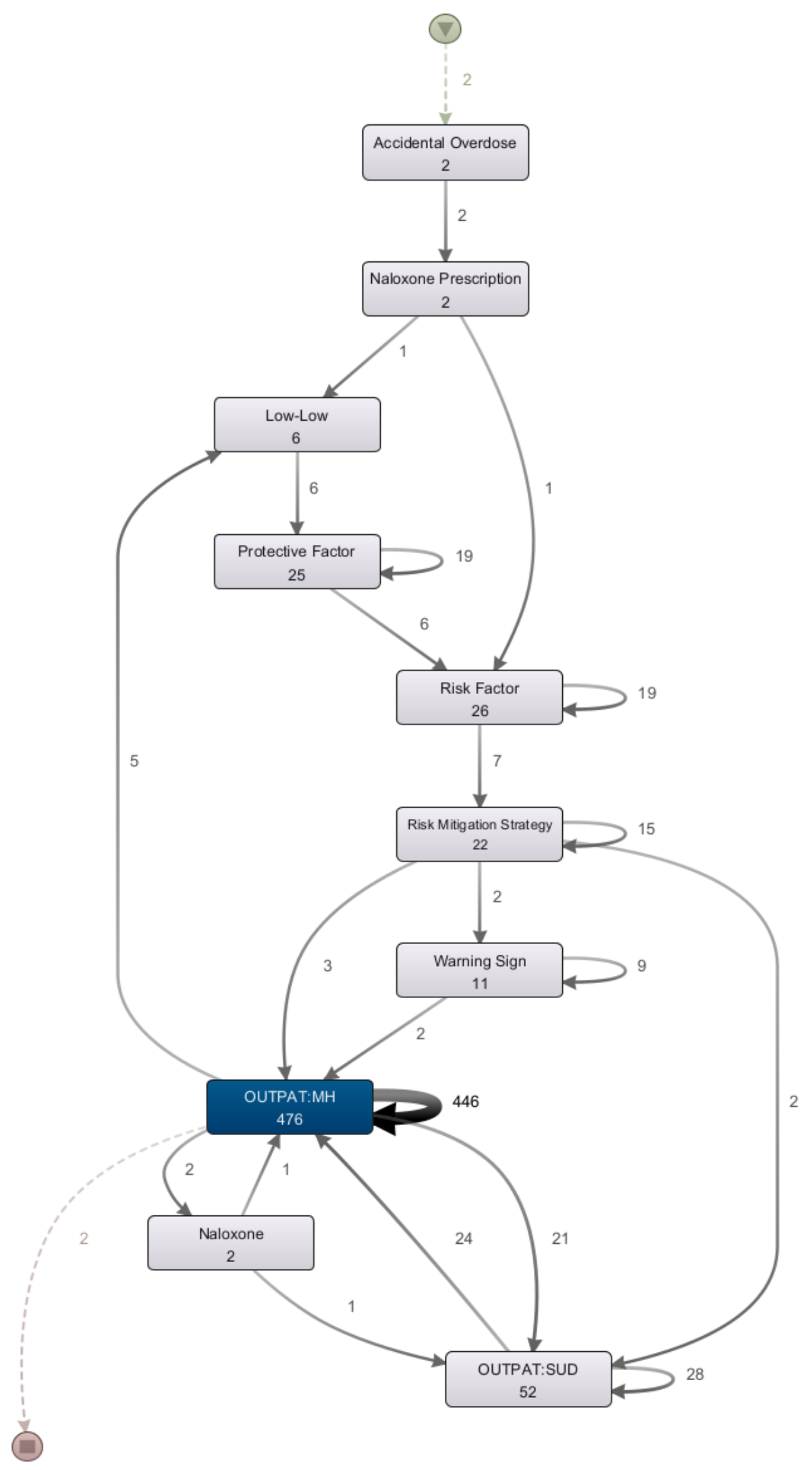

Figure 3. Sample flow of events in two overdose cases. 


\section{RESULTS}

\subsection{DESCRIPTIVE STATISTICS}

In this section, we leveraged the data in Figure 2 and prepared Table 1, which presents the percentage of patients with Naloxone rescue kit fill, outpatient mental health (MH) visit, and outpatient SUD visit. Additionally, we provide the number of days, patients appear in the system (with at least one visit) for SUD and MH visits. There is a total of 31,787 patients who had one of the initial overdose events and we followed these patients.

Table 1 Descriptive statistics to understand the prevalence of follow-up care.

\begin{tabular}{|l|l|l|l|l|l|}
\hline & \% with Naloxone & $\begin{array}{l}\text { \% with SUD } \\
\text { follow-up visit }\end{array}$ & $\begin{array}{l}\text { \% with MH } \\
\text { follow-up visit }\end{array}$ & $\begin{array}{l}\text { Avg \# of days } \\
\text { with SUD visits }\end{array}$ & $\begin{array}{l}\text { Avg \# of days } \\
\text { with MH visits }\end{array}$ \\
\hline Within 7 days & 5.29 & 16.59 & 71.70 & 0.58 days & 2.38 days \\
\hline Within 14 days & 6.65 & 23.33 & 79.88 & 1.17 days & 4.02 days \\
\hline Within 21 days & 7.49 & 26.85 & 83.48 & 1.75 days & 5.41 days \\
\hline Within 28 days & 8.25 & 29.27 & 86.12 & 2.31 days & 6.69 days \\
\hline Within 3 months & 11.88 & 37.06 & 92.32 & 6.02 days & 14.76 days \\
\hline Within 6 months & 15.30 & 41.11 & 93.88 & 9.41 days & 22.37 days \\
\hline Within 1 year & 20.02 & 44.65 & 94.86 & 13.87 days & 32.13 days \\
\hline
\end{tabular}

Additionally, we investigated how many people filled Naloxone prescriptions (i.e., rescue kits). 5,600 patients filled Naloxone prescriptions at least one time. Out of these 5,600 patients, 2,958 of them had a past naloxone prescription filled before the overdose event. There is a total of 5,125 patients who had a past Naloxone prescription. Also, there are 731 patients who had a Naloxone order that was not filled. However, 511 of these patients had another Naloxone prescription after the initial event. The unfilled Naloxone prescriptions can be indicative of dropout of follow-up care and should be further investigated.

\subsection{CARE GAPS}

In this section, we explore the days between visits (included all outpatient MH and SUD, and inpatient $\mathrm{MH}$ and residential). We separated the main cohort of patients into two groups: (i) patients who appear in the system again with another suicide event (not only overdose but all), and (ii) patients who did not have another suicide event. We, then calculated the number of days that passed between their visits. We only included the events that lead to the suicide event for the first group. Figure 4 and 5 present respectively the frequencies of the time intervals for patients who did and did not have another suicide event. 

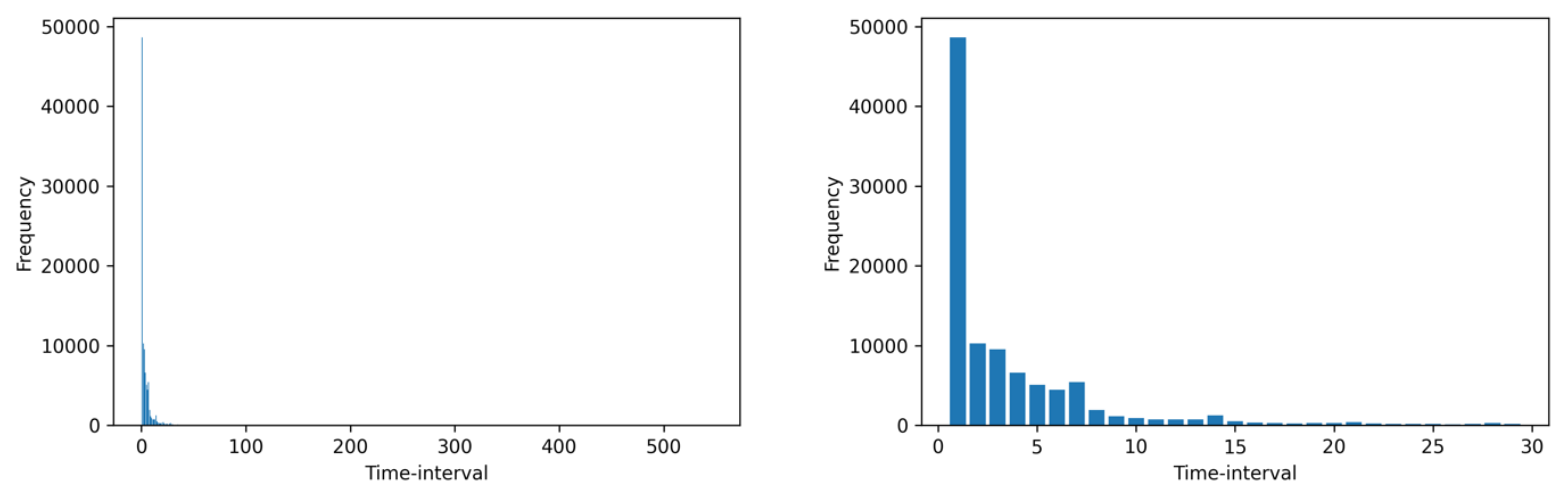

Figure 4 The frequencies of different inter-visit times for the patients who had a follow-up suicide event. The left includes all data, and the right includes only the frequencies for inter-visit times $<30$ days.
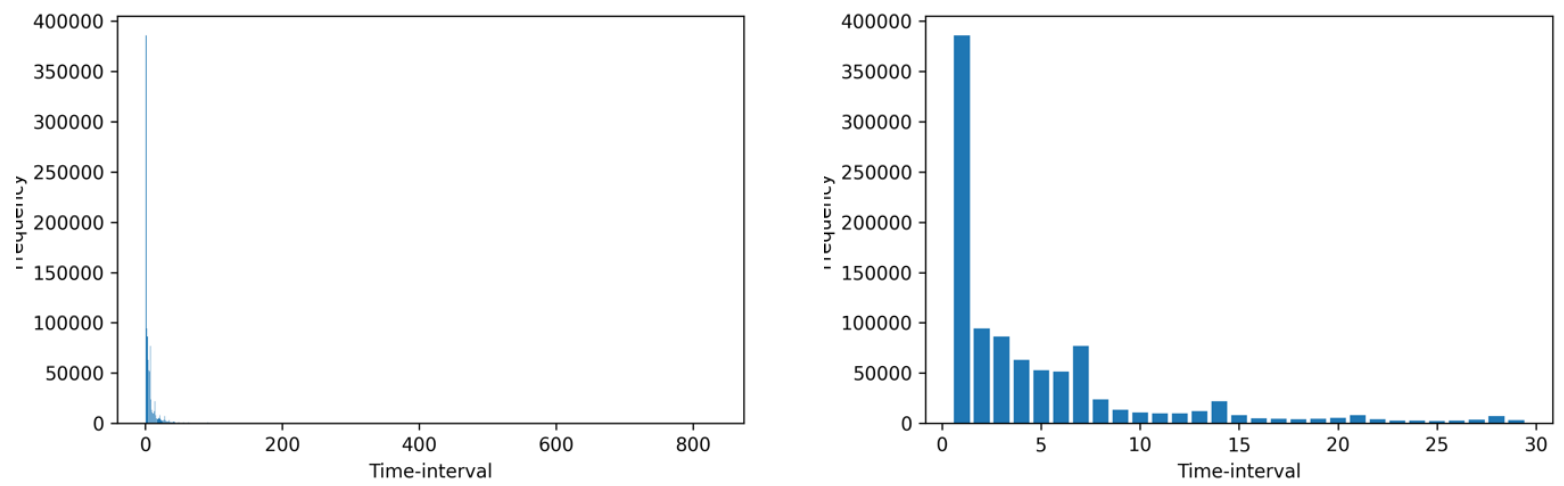

Figure 5 The frequencies of different inter-visit times for the patients who did not have another suicide event. The left includes all data, and the right includes only the frequencies for inter-visit times $<30$ days.

If we examine Figures 4 and 5, we cannot see distributional differences. This may be due to the large sample size and counting inter-visit time for every visit. One interesting observation is that the numbers in the right plots spike at days 7, 14,21, and 28. This is probably an artifact of scheduling follow-up visits in weekly intervals.

Next, we investigate the mean inter-visit times per patient, see Figure 6 and Figure 7.
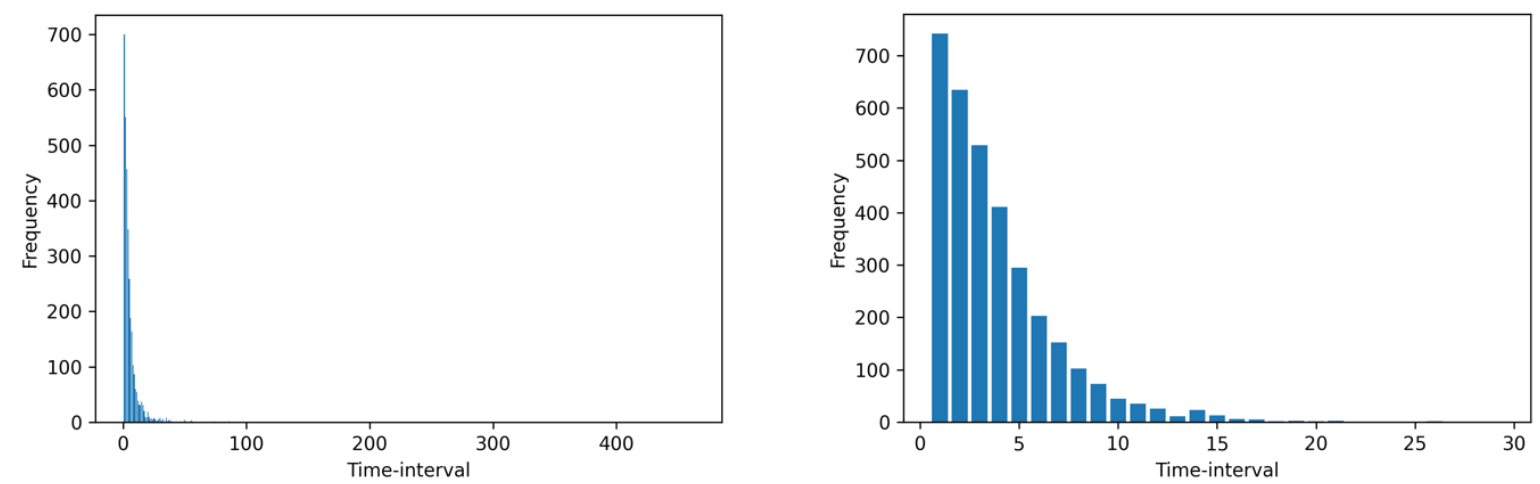

Figure 6 The frequencies (counting patients) of mean inter-visit times for the patients who had a follow-up suicide event. The left includes all the patients; the right includes only the patients whose average inter-visit times $<30$. 

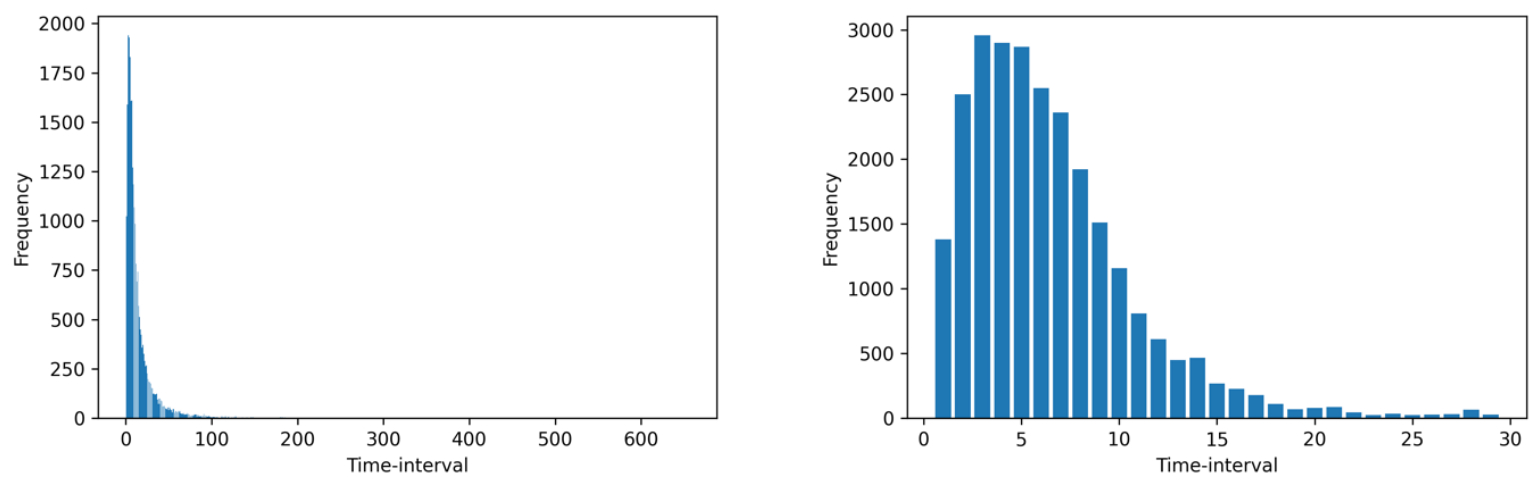

Figure 7 The frequencies (counting patients) of mean inter-visit times for patients who did not have another suicide event. The left includes all the patients, the right only includes the patients whose average inter-visit times $<30$.

The plots on the right exhibit different distribution parameters in Figures 6 and 7. Both seem to be following a Weibull distribution with different parameters ( $\beta$ values). There can be multiple reasons for this observed phenomenon. One reason could be the severity of the conditions for the patients who committed or attempted suicide again. These patients may be more likely to be admitted and have shorter mean inter-visit times. To further investigate this finding, we calculated the number of days patients showed up in a visit continuously (day by day). For example, if a patient shows up on days 3,4 , and 5 consecutively, the event has a duration of three days. If someone showed up on days 1 and 2 and 5, then we count it as two durations, one having two (consecutive) days and the other is one day. Henceforth, in this report, this is termed "durations of visit groups."
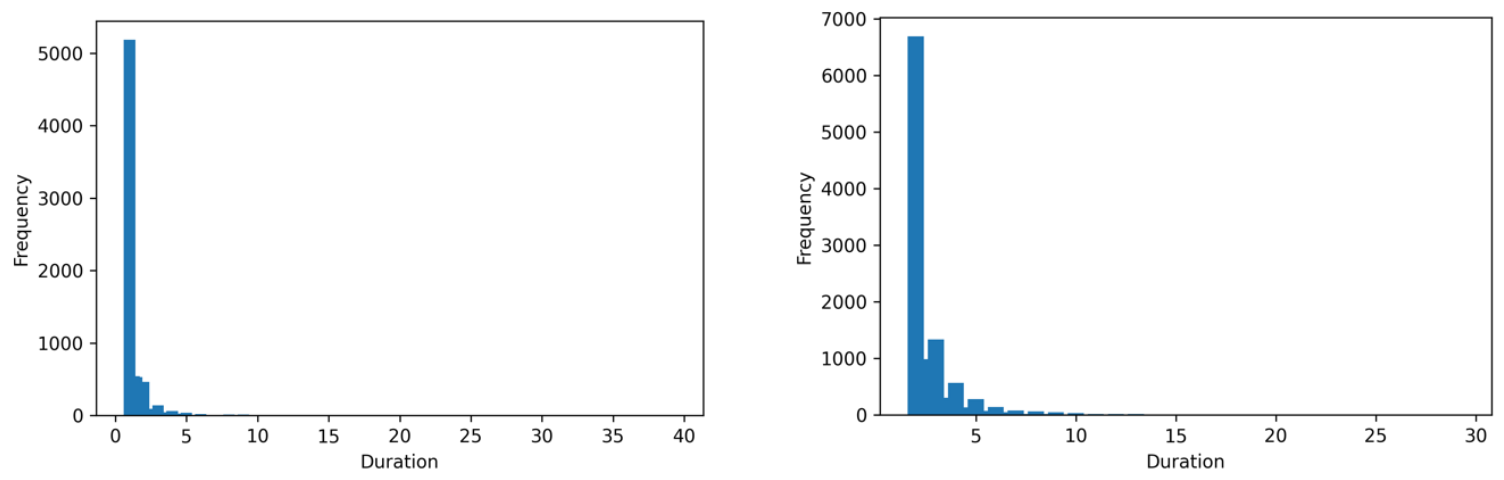

Figure 8 The mean duration (in days) of visit groups for the patients who did not have another suicide event. The left includes all the patients, the right only includes the patients whose mean duration is between 2 and 30. 

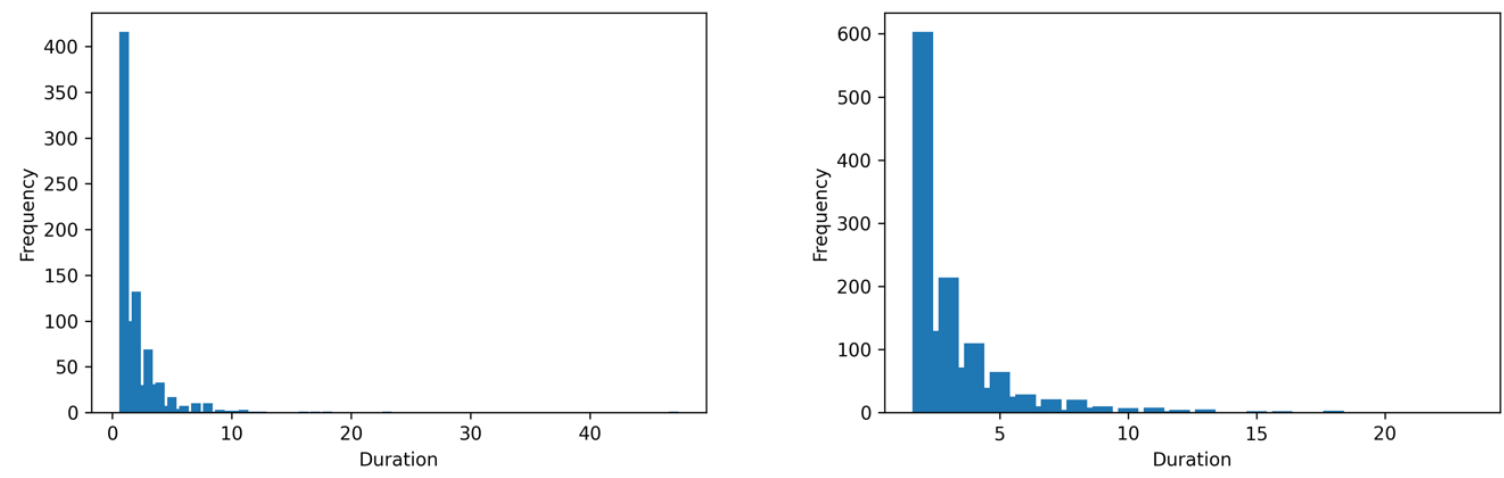

Figure 9 The mean duration (in days) of visit groups for the patients who had a follow-up suicide event. The left includes all the patients, the right only includes the patients whose mean duration is between 2 and 30.

As observed, Figure 9 (patients who had follow-up suicide) has a longer tail relative to the frequencies of shorter durations. Our interpretation is that those patients were likely to have longer visits or groups of visits that follow each other. Again, this finding may be due to the complexity of these patients' cases. Nonetheless, it is something that can be used as a feature to determine what gap is okay for the patients who visit frequently and for longer periods vs. patients who only have a single follow-up visit.

\subsection{CLUSTERING OF PATIENTS}

To answer the third research question, we leveraged the data in Figure 2 to cluster the patients using events data. Working with sequence data can be hard sometimes; but it can probably provide better insights by making use of the temporal dimension. When sequence data contain a lot of activities, which lead to different types of sequences, the process model on the complete data can become too complex to interpret. Clustering similar sequences together for analysis is one way to get a better insights from the sequence data.

Sequence clustering groups similar sequences into clusters based on their similarities. Sequence clustering is useful when there are unknown numbers of similar sequences that need to be identified to gain valuable insights. Sequence clustering can provide better explainable models than a general model fitted on complete data. There are different algorithms for performing sequence clustering including Edit Distance with Hierarchical Clustering, Markov Model-Based Clustering, Dynamic Time Warping, and K-Means. Due to its popularity, we implemented only the K-Means algorithm for the results discussed in this report. As part of our future task, we will compare the performance of K-Means to the other two algorithms mentioned above. This is necessary for us to explore the data from multiple points of view and get a reliable understanding of the sequences.

Understanding the flow of patients care from process model using sequence data can be complex with high dimensional data. This is even more true for applications (as the data in Figure 2) where the sequence data contain a high number of distinct activities and where all the activities need not be equally important. Hence, exploratory data analysis is needed to understand which 
activities are important. Thus, activities with less information can make the models more complex and harder to interpret.

\subsubsection{Data Preprocessing}

For this study, we focus on four columns: ID, event type, event detail, and days. We consider the chronologically combination of events with the same ID as a sequence. We combine the event type and event detail in each record as an event. But we eliminate the event detail for most of events in this stage except for overdose type.

We also observe a lot of repeat events in each sequence. To reduce the computational complexity of the analysis, we keep only one event for the contiguous duplicate events and remove the rest from the sequence.

\subsubsection{Clustering Model}

In this report, we cluster the dataset using sequence graph transform (SGT) embedding and KMeans clustering approach. Based on the results, we implemented the process map for each cluster.

We show our sequence approach in Figure 10. Formally, sequence data can be given as $S=$ $\left\{s_{1}, s_{2}, \ldots, s_{n}\right\}$. After data preprocessing, SGT embedding was used to convert text sequences into a finite-dimensional feature space, which is stored in a $v \times v$ asymmetric matrix ( $v$ is the number of unique events in $s$ ). SGT can capture both short and long patterns in sequences and provide an accurate location distance-based measurement between each event in sequences. Then, a traditional clustering method can be used on the sequence embedding matrix in the final step.

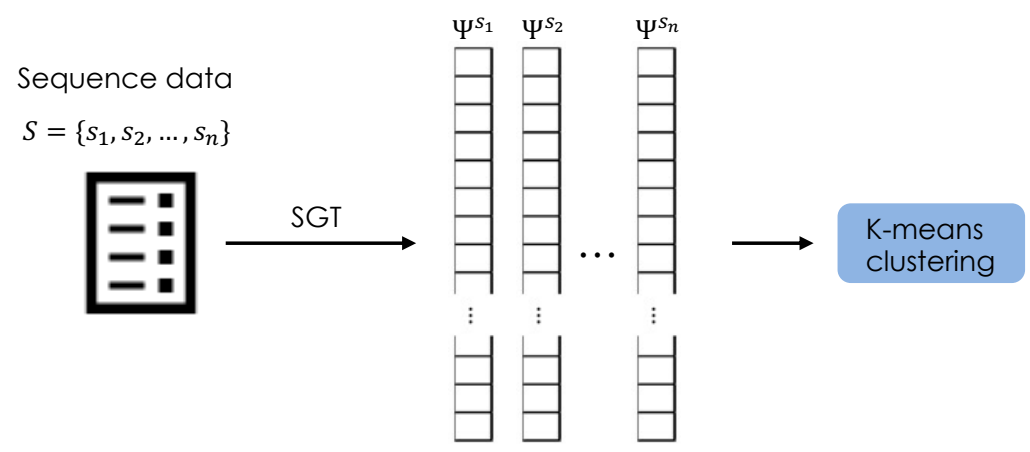

Figure 10 Diagram of sequence clustering method.

The SGT function between two events in a sequence is given as:

$$
\psi_{u v}=\frac{\sum_{\forall(l, m) \epsilon \Lambda_{u v}(s)} e^{-|m-l|}}{\left|\Lambda_{u v}(s)\right| / L_{s}}
$$


where $\Lambda_{u v}(s)$ shows all the positions pairs $(l, m)$ for event $u$ and $v$ in sequence $s, s_{l}=u, s_{m}=v$, $L$ is the number of position pairs for $u$ and $v$ in $s$. In Figure 11, we show an example of how to calculate the embedding between $\mathrm{A}$ and $\mathrm{B}$ in the given sequence. There are 5 pairs of position between $\mathrm{A}$ and $\mathrm{B}$.

Thus, $\Lambda_{A B}=\{(2,5) ;(3,5) ;(2,8) ;(3,8) ;(6,8)\}$ and

$\psi_{u v}=\frac{\sum_{\forall(l, m) \epsilon \Lambda_{A B}(s)} e^{-|m-l|}}{\left|\Lambda_{A B}(s)\right| / L_{S}}=\frac{e^{-|5-2|}+e^{-|5-3|}+e^{-|8-2|}+e^{-|8-3|}+e^{-|8-6|}}{5}=0.066$.

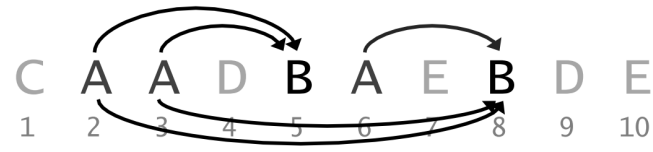

Figure 11 Example of SGT function.

After the text events are transferred to embedding matrices, K-Means clustering is applied to divide the sequences into several groups. The sequences in each group/cluster are supposed to have similar characteristics or patterns. We implemented K-Means for $k$ (the number of clusters) equals to $2,3,5$, and 10 , respectively, to capture the common patterns in each group.

\subsubsection{Clustering Results}

Table 2 presents the statistics for each cluster in the 2 clusters implementation; it has the number of patients, the mean duration, and the max duration for each cluster. Table 4, Table 5, and Table 5 present the same information for the 3,5 , and 10 clusters, respectively.

Table 2 Summaries of statistics for 2 clusters model

\begin{tabular}{|c|c|c|c|}
\hline Cluster & $\begin{array}{c}\text { number of } \\
\text { patients }\end{array}$ & $\begin{array}{c}\text { mean duration } \\
\text { (days) }\end{array}$ & $\begin{array}{c}\text { max duration } \\
\text { (days) }\end{array}$ \\
\hline $\mathbf{1}$ & 1352 & 177.2 & 885 \\
\hline $\mathbf{2}$ & 796 & 224.6 & 823 \\
\hline
\end{tabular}

Table 3 Summaries of statistics for 3 clusters model

\begin{tabular}{|c|c|c|c|}
\hline Cluster & $\begin{array}{c}\text { number of } \\
\text { patients }\end{array}$ & $\begin{array}{c}\text { mean duration } \\
\text { (days) }\end{array}$ & $\begin{array}{c}\text { max duration } \\
\text { (days) }\end{array}$ \\
\hline $\mathbf{1}$ & 612 & 196.3 & 777 \\
\hline $\mathbf{2}$ & 1222 & 177.6 & 885 \\
\hline $\mathbf{3}$ & 314 & 258.4 & 823 \\
\hline
\end{tabular}


Table 4 Summaries of statistics for 5 clusters model

\begin{tabular}{|c|c|c|c|}
\hline Cluster & $\begin{array}{c}\text { number of } \\
\text { patients }\end{array}$ & $\begin{array}{c}\text { mean duration } \\
\text { (days) }\end{array}$ & $\begin{array}{c}\text { max duration } \\
\text { (days) }\end{array}$ \\
\hline $\mathbf{1}$ & 215 & 230.5 & 818 \\
\hline $\mathbf{2}$ & 1093 & 150.5 & 848 \\
\hline $\mathbf{3}$ & 334 & 163.3 & 777 \\
\hline $\mathbf{4}$ & 293 & 354.8 & 885 \\
\hline $\mathbf{5}$ & 213 & 214.9 & 823 \\
\hline
\end{tabular}

Table 5 Summaries of statistics for 10 clusters model

\begin{tabular}{|c|c|c|c|}
\hline Cluster & $\begin{array}{c}\text { number of } \\
\text { patients }\end{array}$ & $\begin{array}{c}\text { mean duration } \\
\text { (days) }\end{array}$ & $\begin{array}{c}\text { max duration } \\
\text { (days) }\end{array}$ \\
\hline $\mathbf{1}$ & 148 & 194.4 & 688 \\
\hline $\mathbf{2}$ & 643 & 231.1 & 848 \\
\hline $\mathbf{3}$ & 144 & 285.3 & 771 \\
\hline $\mathbf{4}$ & 141 & 347.9 & 823 \\
\hline $\mathbf{5}$ & 102 & 265.8 & 729 \\
\hline $\mathbf{6}$ & 447 & 30.7 & 706 \\
\hline $\mathbf{7}$ & 101 & 98.2 & 674 \\
\hline $\mathbf{8}$ & 130 & 134 & 777 \\
\hline $\mathbf{9}$ & 168 & 398 & 766 \\
\hline $\mathbf{1 0}$ & 124 & 127.3 & \\
\hline & & & 885 \\
\hline
\end{tabular}

\subsubsection{Visualization of the Clusters}

Visualization is a powerful tool that can help explore common patterns exhibited in the data. Thus, we visualize the results for each cluster as a process model. The models for the 2 clusters are shown in Figures 12 and 13; models for the 3 clusters are shown in Figures 14 to 16; models for the 5 clusters are shown in Figures 17 to 21; and the models for the 10 clusters are shown in Figures 22 to 31 . Based on these results, there is no clear distinction between the clusters. Specifically, each clustering model suggests that the variability in the process model may not be purely data driven. We may need some empirical insights based on experts' knowledge of the process to better capture and understand the care process. We will explore this idea in future studies. 


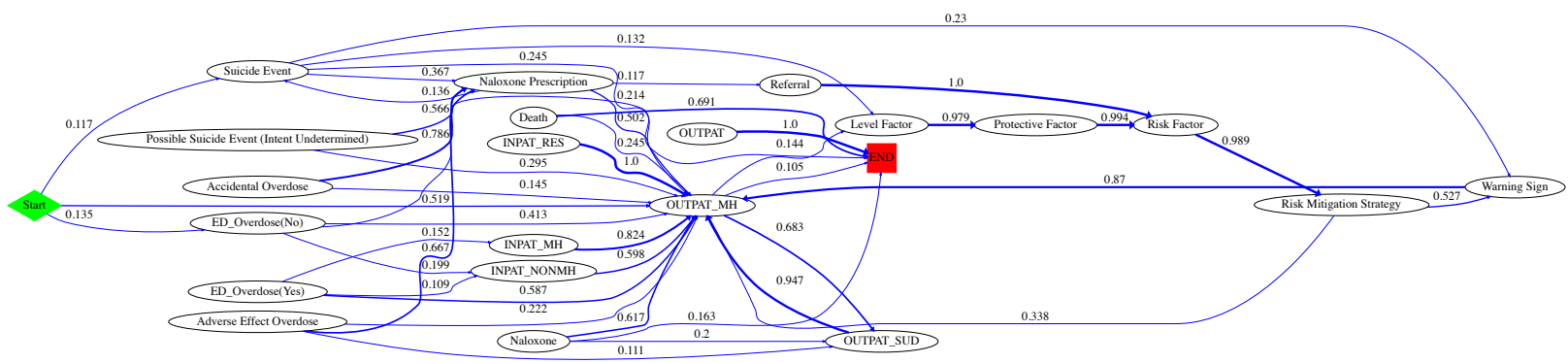

Figure 12 Process Model for Cluster 1 of 2.

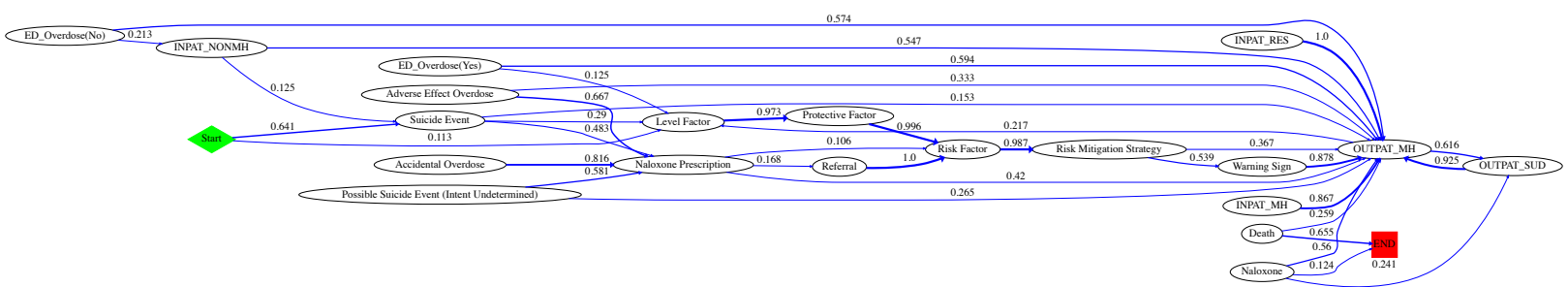

Figure 13 Process Model for Cluster 2 of 2.

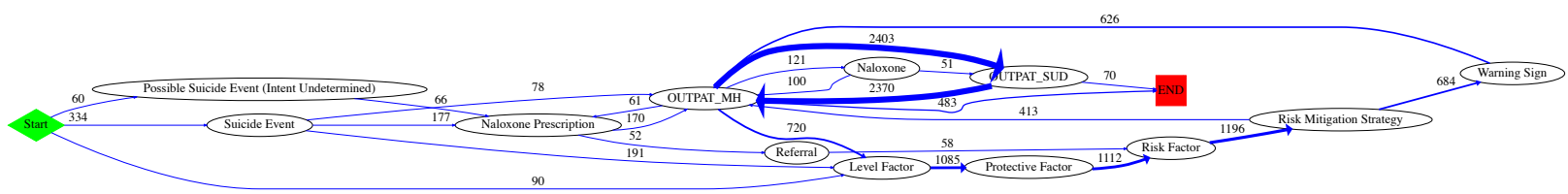

Figure 14 Process Model for Cluster 1 of 3.

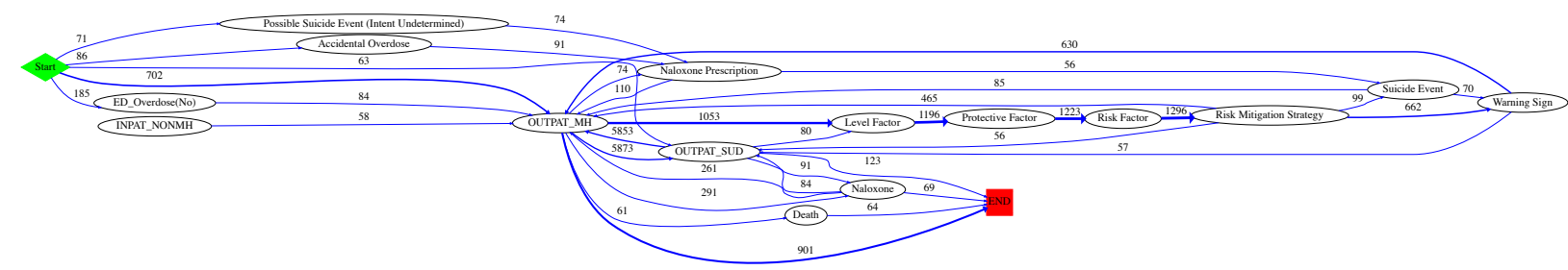

Figure 15 Process Model for Cluster 2 of 3.

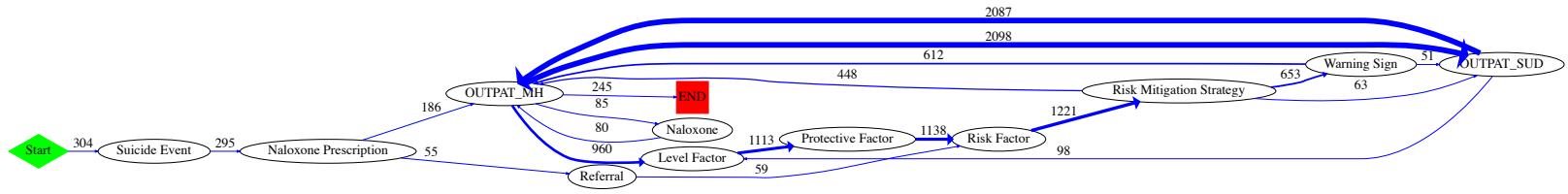

Figure 16 Process Model for Cluster 3 of 3. 


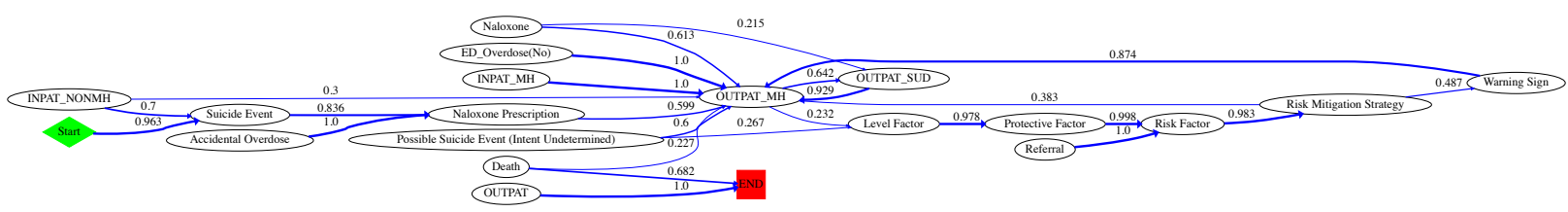

Figure 17 Process Model for Cluster 1 of 5.

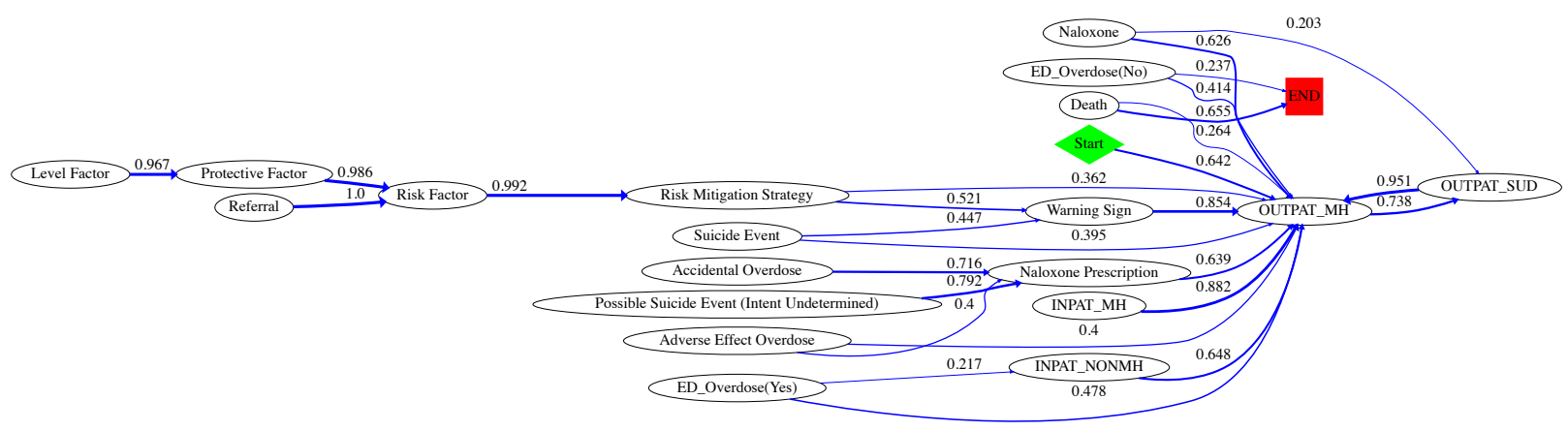

Figure 18 Process Model for Cluster 2 of 5.

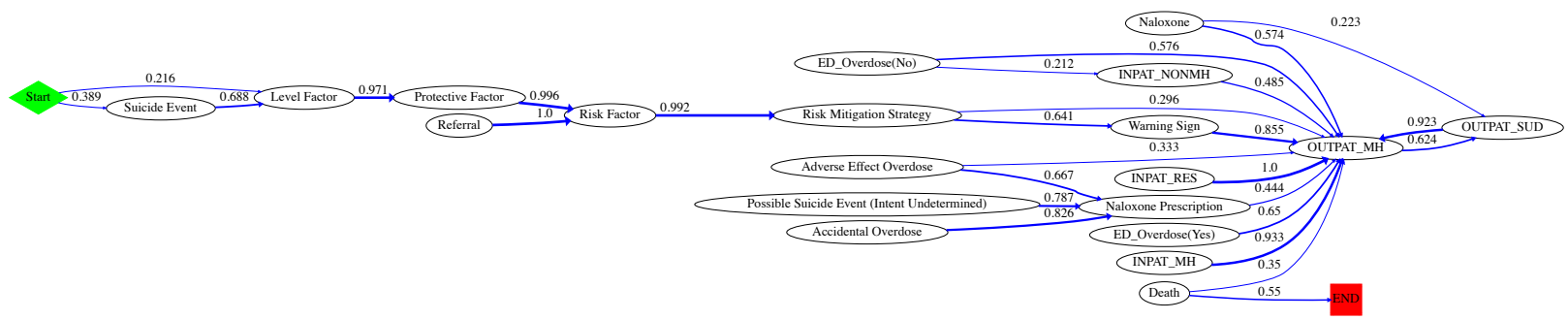

Figure 19 Process Model for Cluster 3 of 5.

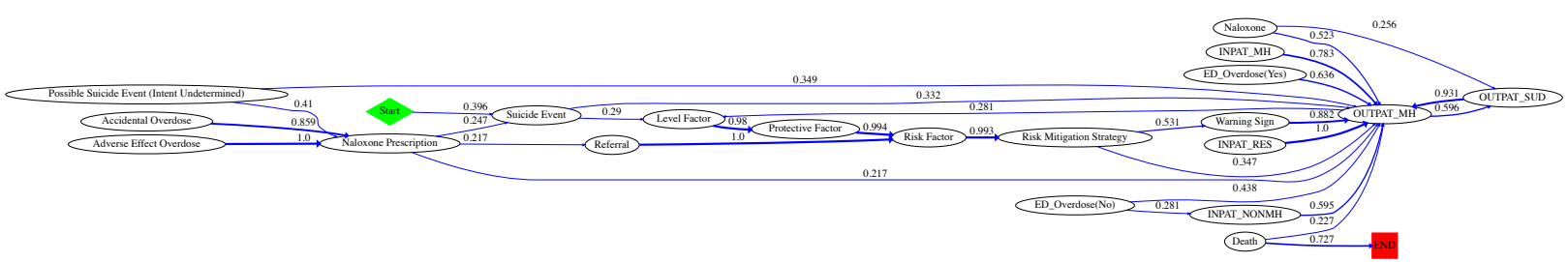

Figure 20 Process Model for Cluster 4 of 5.

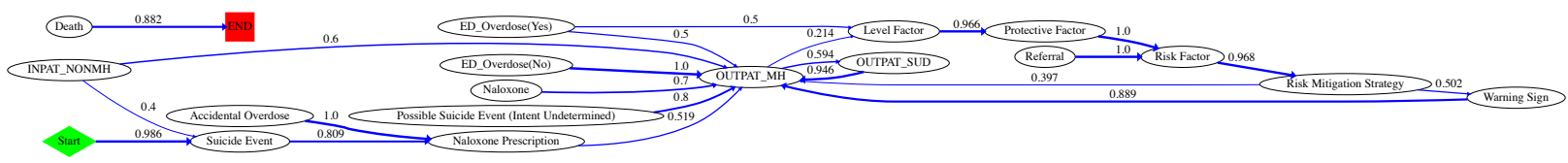

Figure 21 Process Model for Cluster 5 of 5. 


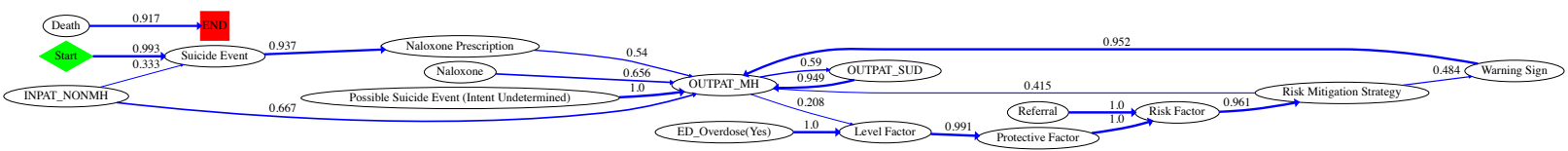

Figure 22 Process Model for Cluster 1 of 10.

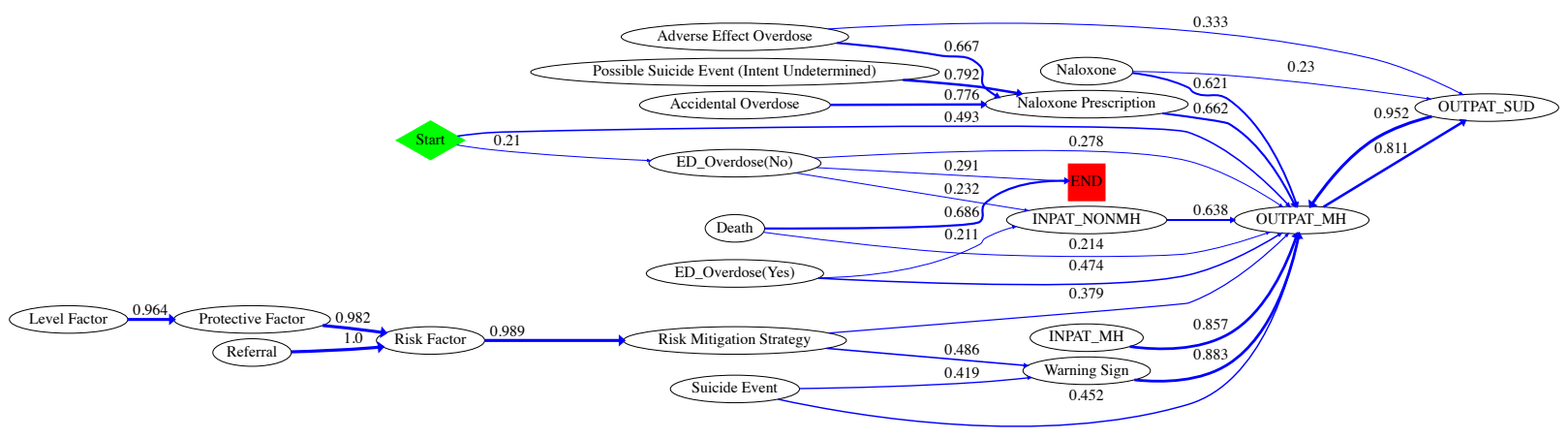

Figure 23 Process Model for Cluster 2 of 10.

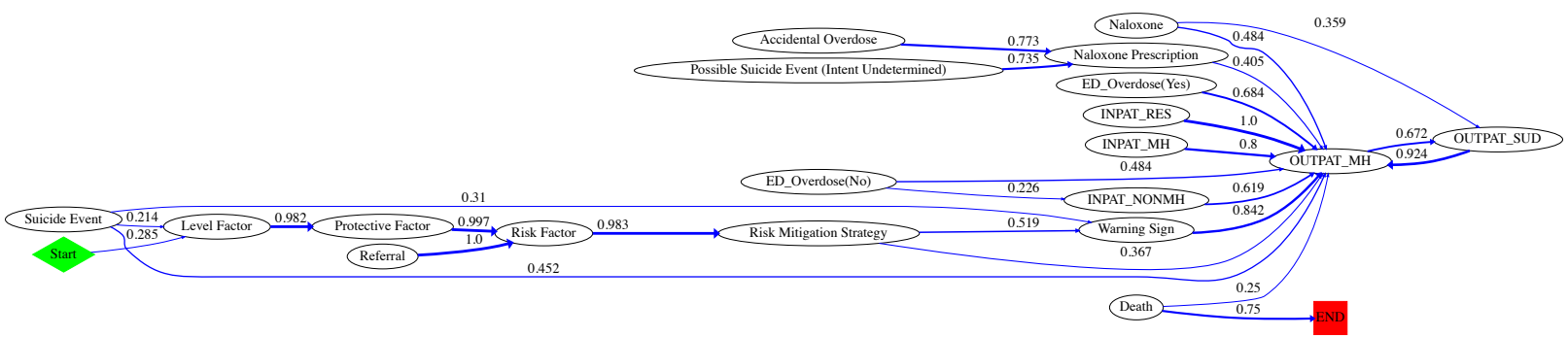

Figure 24 Process Model for Cluster 3 of 10.

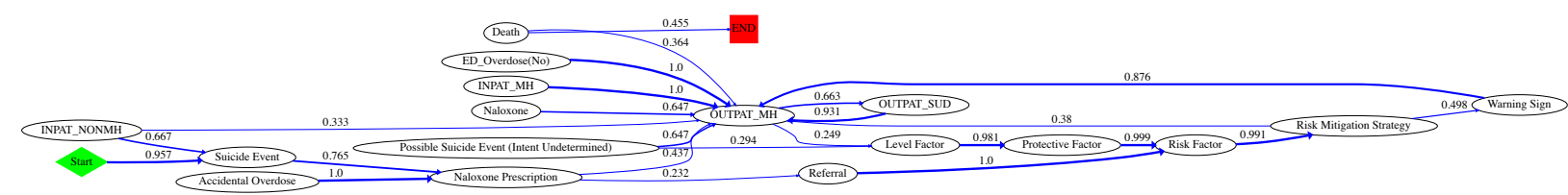

Figure 25 Process Model for Cluster 4 of 10.

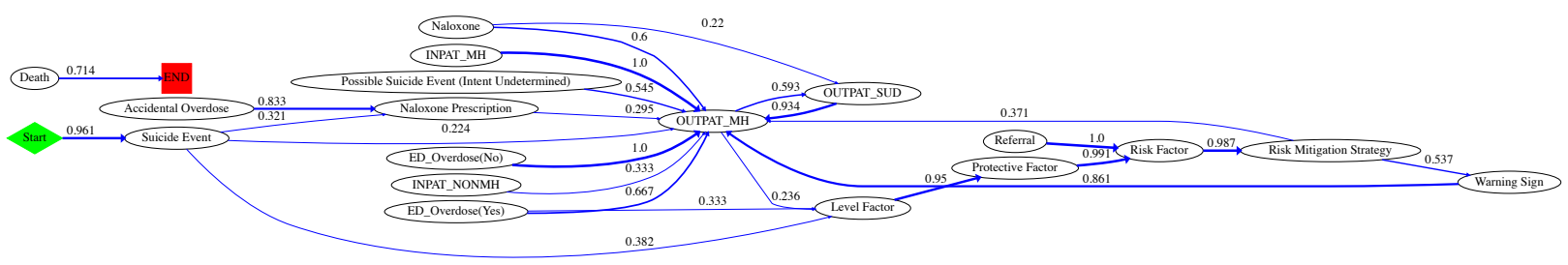

Figure 26 Process Model for Cluster 5 of 10. 


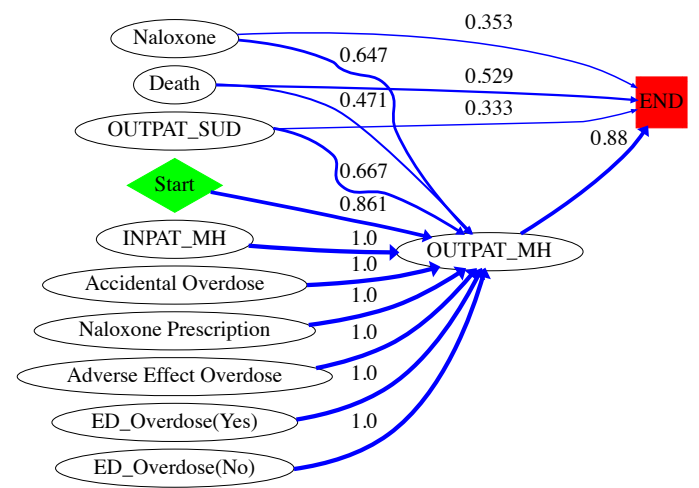

Figure 27 Process Model for Cluster 6 of 10.

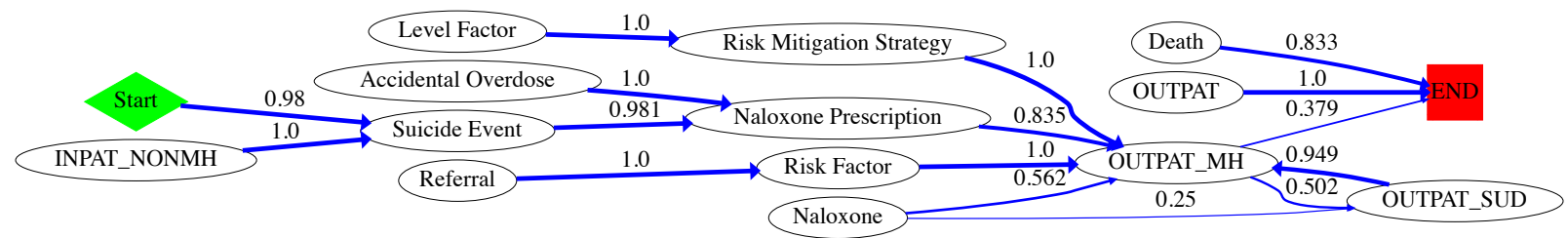

Figure 28 Process Model for Cluster 7 of 10.

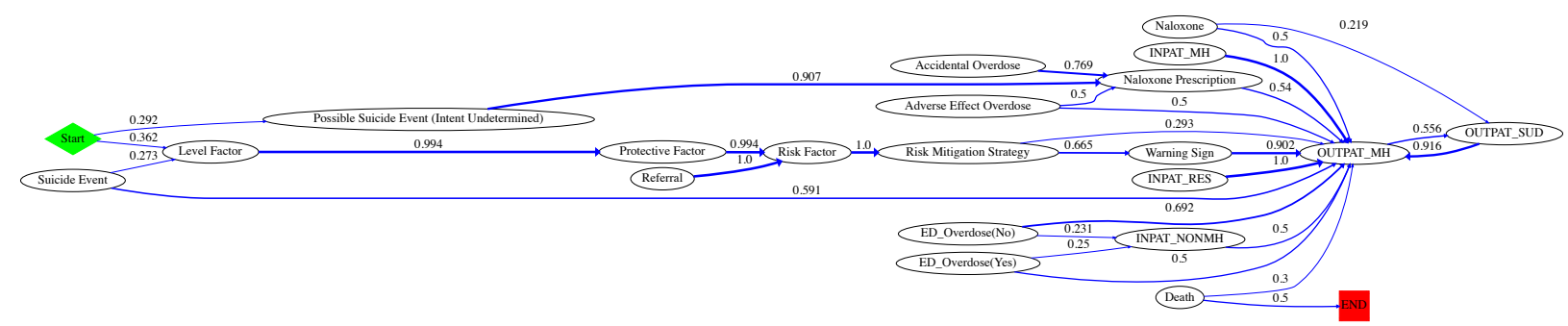

Figure 29 Process Model for Cluster 8 of 10.

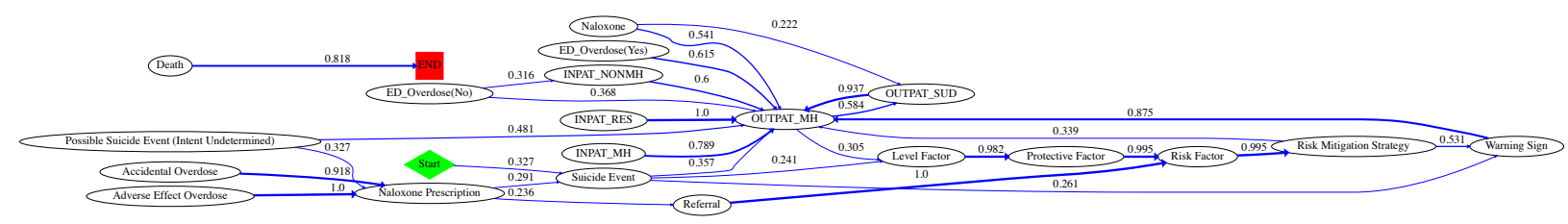

Figure 30 Process Model for Cluster 9 of 10.

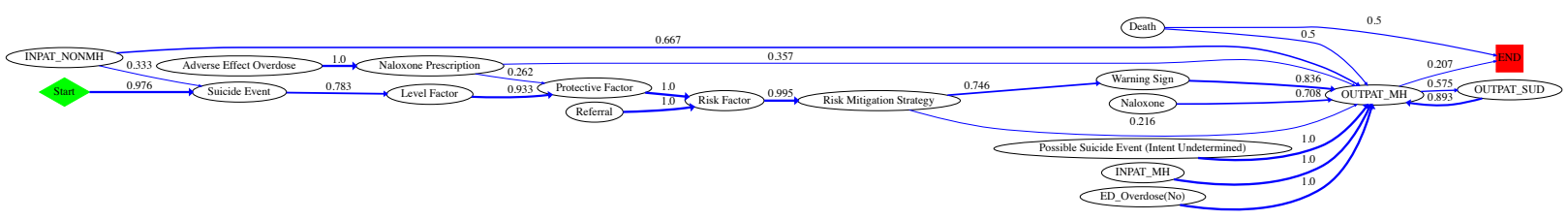

Figure 31 Process Model for Cluster 10 of 10. 


\section{DISCUSSIONS AND FUTURE WORK}

In this short-term effort, we attempted to understand the follow-up care data that can be extracted from the VHA CDW and presented some insights that can potentially turn into follow-up research questions. Our results support the VHA's statement in that there is a lot of room for improvement in the process around post-follow-up care for SUD cases [3][8]. The results presented herein show that patients receive more specialty mental health care than specialty SUD services. In an ideal world, specialty mental health is fully competent in providing evidencebased substance use disorder services. But many general mental health providers may not feel comfortable providing evidence-based services for substance use disorders [13]. Patients are likely to get what appears to be an appropriate follow-up but then not get the evidence-based SUD care that they need to prevent additional overdoses and other adverse outcomes [16]. This is an area for further investigation.

During our studies, members of the VHA informed and introduced us to the VHA CDW data domains that we were not familiar with, and given the short-term of this project, we couldn't explore enough to provide more insights and perform further analyses. Also, we will consider refining the current selection of CDW features to include only those that are more representative of the overdose problem domain.

Medications for OUD (buprenorphine formulations, depot naltrexone, or treatment in a licensed opioid treatment program) are the most important of these evidence-based treatments for OUD care. Understanding where care tends to break down in terms of initiating and maintaining patients on these medications post-overdose is important and as next steps, the team is aiming to dive into that.

Regarding the care gap calculations, the distributions have shown differences between people who had a follow-up suicide event and the people who did not have a follow-up event. We believe that this may be due to the complexities of the cases for the people who had another event. They are more likely to have shorter mean inter-visit times and longer durations (the number of consecutive days with visits). This finding can be used as a feature to separate people who are more likely to have a follow-up event and it warrants further investigation. Additionally, the dataset can be further stratified based on different socio-economic characteristics of the patients, different time frames and similar distributions can be extracted.

Another interesting venue of research would be to create composite follow-up events that are defined based on these findings and subject matter expertise. Events like "Naloxone ordered but not filled", "has a past naloxone before the overdose event", "CSRE evaluation got worse", "the existence of a certain number of risk mitigation strategies/ risk factors/ warning signs", "had a care gap that is larger than the 95 percentile of the group and ended up in a visit with longer duration" etc. can be generated. These composite events may be able to provide more interesting findings than the raw data we created (Figure 2) using visualizations like process models and Markovian models. Additional data resources such as canceled consults or appointments can also be used as new features that would give additional insights on the community care appointments and forwarded/referred appointments to other facilities that can be cancelled due to proximity concerns. 
With respect to clustering of patients, the research team will be discussing the clustering results with experts at the VHA to understand if there are any insights in the process models that could help with further analysis, especially with respect to understanding events with good or bad outcome. Furthermore, the team will explore additional clustering algorithms for evaluating consistency in the results. Since we don't know the optimal number of clusters in the data, the team will also investigate the use of advanced methods for estimating a lower bound for the number of clusters.

\section{REFERENCES}

[1] Maloney, E., Degenhardt, L., Darke, S., \& Nelson, E. C. (2009). Are non-fatal opioid overdoses misclassified suicide attempts? Comparing the associated correlates. Addictive behaviors, 34(9), 723.

[2] Ranade, R., Wunder, J., Terzian, M., \& Ungureanu, I. (2020). Opioids and suicide: opportunities for comprehensive prevention. Journal of public health management and practice, 26(3), 291-293.

[3] Oliva, E. M., Bowe, T., Tavakoli, S., Martins, S., Lewis, E. T., Paik, M., ... \& Trafton, J. A. (2017). Development and applications of the Veterans Health Administration's Stratification Tool for Opioid Risk Mitigation (STORM) to improve opioid safety and prevent overdose and suicide. Psychological services, 14(1), 34.

[4] E. M. Oliva et al., "Opioid overdose education and naloxone distribution: Development of the Veterans Health Administration's national program," Journal of the American Pharmacists Association, vol. 57, no. 2, pp. S168-S179. e4, 2017.

[5] E. M. Oliva et al., "Patient perspectives on an opioid overdose education and naloxone distribution program in the US Department of Veterans Affairs," Substance Abuse, vol. 37, no. 1, pp. 118-126, 2016.

[6] L. A. Lin, T. Peltzman, J. F. McCarthy, E. M. Oliva, J. A. Trafton, and A. S. Bohnert, "Changing trends in opioid overdose deaths and prescription opioid receipt among veterans," American journal of preventive medicine, vol. 57, no. 1, pp. 106-110, 2019.

[7] S. C. Mudumbai et al., "Overdose risk associated with opioid use upon hospital discharge in veterans health administration surgical patients," Pain Medicine, vol. 20, no. 5, pp. 1020-1031, 2019.

[8] E. M. Oliva et al., "Associations between stopping prescriptions for opioids, length of opioid treatment, and overdose or suicide deaths in US veterans: observational evaluation," bmj, vol. 368, 2020.

[9] H. K. Koh, C. Brach, L. M. Harris, and M. L. Parchman, "A proposed 'health literate care model'would constitute a systems approach to improving patients' engagement in care," Health affairs, vol. 32, no. 2, pp. 357-367, 2013.

[10] E. H. Wagner, B. T. Austin, and M. Von Korff, "Organizing care for patients with chronic illness," The Milbank Quarterly, pp. 511-544, 1996.

[11] J. R. Langabeer II, A. Yatsco, and T. Champagne-Langabeer, "Telehealth sustains patient engagement in OUD treatment during COVID-19," Journal of Substance Abuse Treatment, vol. 122, p. 108215, 2021.

[12] J. Massey et al., "Opioid overdose outbreak-West Virginia, August 2016," MMWR. Morbidity and mortality weekly report, vol. 66, no. 37, p. 975, 2017. 
[13] A. C. Tsai et al., "Stigma as a fundamental hindrance to the United States opioid overdose crisis response," PLoS medicine, vol. 16, no. 11, p. e1002969, 2019.

[14] G. G. Carroll et al., "Buprenorphine field initiation of ReScue treatment by emergency medical services (Bupe FIRST EMS): A case series," Prehospital Emergency Care, vol. 25, no. 2, pp. 289-293, 2021.

[15] J. R. Langabeer, D. Persse, A. Yatsco, M. M. O’Neal, and T. Champagne-Langabeer, "A framework for EMS outreach for drug overdose survivors: a case report of the Houston Emergency Opioid Engagement System," Prehospital emergency care, vol. 25, no. 3, pp. 441-448, 2021.

[16] J. J. Carroll, T. C. Green, and R. K. Noonan, "Evidence-based strategies for preventing opioid overdose: What's working in the United States," National Center for Injury Prevention and Control, Centers for Disease Control and Prevention, 2018. 